\title{
Midfoot Charcot Arthropathy: Overview and Surgical Management
}

${ }^{1}$ Sundararajan Silvampatti, ${ }^{2} \mathrm{HS}$ Nagaraja, ${ }^{3} \mathrm{~S}$ Rajasekaran

\begin{abstract}
Midfoot Charcot arthropathy is a progressive deforming condition characterized by recurrent ulceration leading to high morbidity and amputation with lack of timely intervention. Nonoperative treatment is largely reserved for acute phase disease. Recent trend in management is early surgical interventions which could alter deforming forces and prevent deformity progression, as well as surgeries which provide osseously stable plantigrade foot. However, there are no clear-cut evidencebased guidelines regarding timing of interventions and method of techniques in surgical stabilization. This study discusses about surgical technique in the management of midfoot Charcot.
\end{abstract}

Keywords: Early surgery, External fixation, Fusion bolts, Internal fixation, Midfoot charcot.

How to cite this article: Silvampatti S, Nagaraja HS, Rajasekaran S. Midfoot Charcot Arthropathy: Overview and Surgical Management. J Foot Ankle Surg (Asia-Pacific) 2016;3(2):97-106.

\section{Source of support: Nil}

Conflict of interest: None

\section{INTRODUCTION}

Charcot neuroarthropathy (CNA) is a chronic debilitating limb-threatening condition affecting musculoskeletal system characterized by progressive joint dislocation, pathological fractures, deformities, ulcer formation and leads to disability and even amputation. ${ }^{1,2}$ Midfoot CNA leads to collapse of the arch, rocker bottom deformity, which alters weight distribution causing point loading over plantar bony prominence resulting in ulcer formation. ${ }^{3}$ Charcot neuroarthropathy profoundly reduces the quality of life and is associated with premature mortality. ${ }^{4,5}$ Conservative management of CNA consisting of total contact cast and off-loading was advocated as the first line treatment till recently. But conservative method prolongs treatment duration, reduces quality of life, and carries recurrent ulceration rates up to 30 to $50 \%$

\footnotetext{
${ }^{1}$ Consultant, ${ }^{2}$ Registrar, ${ }^{3}$ Head

${ }^{1-3}$ Department of Orthopedics, Ganga Hospital, Coimbatore Tamil Nadu, India

Corresponding Author: Sundararajan Silvampatti, Consultant Department of Orthopedics, Ganga Hospital, Coimbatore, Tamil Nadu, India, Phone: +914222485000, e-mail: sundarbone70@ hotmail.com
}

and extremities with ulcers carry high-risk for amputation with reported annual limb amputation rate of 1 to $5 \% .^{6-12}$ Current trend is early diagnosis of foot at risk and surgical stabilization aiming to improve quality of life by not only salvaging the foot, but also by providing stable plantigrade, infection-free, ulcer-free foot, which can allow independent ambulation. ${ }^{13,14}$ Studies have shown that complication rate after early surgery is comparable to those after failed conservative method, i.e., secondary surgery. ${ }^{1}$ This study intends to provide details about current surgical indications and various surgical methods for midfoot CNA.

\section{EPIDEMIOLOGY AND PATHOGENESIS}

Jordan $^{15}$ first described CNA in relation to diabetes mellitus. Diabetes mellitus is the commonest cause in developing world and other causes are peripheral neuropathy due to leprosy, syringomyelia, alcohol abuse, and denervated limb. ${ }^{16}$ Usually, this disease occurs in 4 th to 5 th decade, many years after the onset of diabetes mellitus. ${ }^{17}$ Overall incidence among diabetic patients is 0.3 to $2.5 \%{ }^{18}$ and it is as high as $13 \%$ in patients attending highrisk diabetic foot clinic. ${ }^{17,19}$ Incidence in patients with diabetic neuropathy is $16 \%$ and bilateral involvement is reported in $30 \%$ of patients. ${ }^{20,21}$

Pathogenesis of CNA is poorly understood and various theories put forward are deficiencies in spinal trophic centers by Jean Martin Charcot (French theory), neurotraumatic theory by Volkmann and Virchow (German theory), and neurovascular theory by Finsterbush and Friedman. ${ }^{22-25}$ But, now it is generally thought to be due to combination of neurotraumatic and neurovascular theories wherein autonomic neuropathy leads to increase in blood flow, osteopenia, and weak bones. Motor neuropathy leads to muscle imbalance and abnormal stress on weak bones which remains unrecognized due to sensory neuropathy leading to fractures, dislocations, deformities, and ulcer progression which sets vicious cycle by further increasing the blood flow. ${ }^{26-28}$

\section{PREDILECTION FOR MIDTARSAL JOINTS}

Charcot neuroarthropathy commonly involves midfoot joints that are mainly supported by ligaments, due to combination of multiple factors. The most important factor is equinus contracture. Patients with CNA show high plantar pressures in metatarsophalangeal joints due to equinus 
contracture, with forefoot acting as a lever which results in midfoot collapse on weightbearing. ${ }^{29,30}$ Another factor is the motor neuropathy, which leads to unopposed action of plantarflexors especially tendoachilles in comparison to dorsiflexors. This causes heel to remain off-the-ground during stance phase as well as, it alters ligament integrity. So, on transmitting whole body weight across midtarsal joints, the resultant shearing forces and weak ligaments cause midtarsal joint subluxation, fractures, and dislocation. The other factors, such as low bone mineral density seen on these patients' lead to CNA. ${ }^{31}$

\section{CLASSIFICATION}

\section{Modified Eichenholtz Classification ${ }^{27}$ (Table 1)}

It describes the stages of progression of disease based on clinical and radiological findings. It is useful for treatment decision-making.

\section{Anatomical Classification by Sanders and Frykberg $^{16}$ (Table 2)}

This classification is more useful clinically as complications and healing depend on site of involvement.

\section{CLINICAL PRESENTATION AND INVESTIGATIONS}

High index of suspicion is needed for diagnosing CNA of foot. Early diagnosis is difficult due to absence of pain. ${ }^{32,33}$ In the early stage first signs of CNA are swelling, local

Table 1: Modified Eichenholtz classification

\begin{tabular}{|c|c|c|}
\hline Stage & Clinical findings & Radiological findings \\
\hline 0 & $\begin{array}{l}\text { Loss of protective } \\
\text { sensation with } \\
\text { erythema, swelling, } \\
\text { clinical instability }\end{array}$ & Normal \\
\hline $\begin{array}{l}1 \text { Acute } \\
\text { (fragmentation) } \\
\text { stage }\end{array}$ & $\begin{array}{l}\text { Increased } \\
\text { ligamentous laxity } \\
\text { Continued warmth } \\
\text { and swelling }\end{array}$ & $\begin{array}{l}\text { Osteopenia, } \\
\text { periarticular } \\
\text { fragmentation, fracture, } \\
\text { and subluxation }\end{array}$ \\
\hline $\begin{array}{l}2 \text { Quiescent } \\
\text { (coalescence) } \\
\text { stage }\end{array}$ & $\begin{array}{l}\text { Reduced warmth } \\
\text { and swelling }\end{array}$ & $\begin{array}{l}\text { Absorption of debris, } \\
\text { early fusion, and } \\
\text { sclerosis }\end{array}$ \\
\hline $\begin{array}{l}3 \text { Resolution stage } \\
\text { (consolidation) }\end{array}$ & $\begin{array}{l}\text { Absence of } \\
\text { inflammation }\end{array}$ & $\begin{array}{l}\text { Joint arthrosis, } \\
\text { osteophytes, } \\
\text { subchondral sclerosis }\end{array}$ \\
\hline
\end{tabular}

Table 2: Sanders and Frykberg anatomical classification

\begin{tabular}{ll}
\hline Type & Site of involvement \\
\hline I & Forefoot - Metatarsophalangeal, interphalangeal \\
II & Tarso metatarsal joint - Most common \\
III & Midtarsal joint \\
IV & Ankle and subtalar joints \\
V & Calcaneum \\
\hline
\end{tabular}

rise of temperature, erythema, joint effusion, and loss of sensation. ${ }^{31}$ Pain may be present in $75 \%$ of patients and ulcers in $40 \%$ at the time of presentation. ${ }^{19}$ Advanced stage presents with instability, rocker bottom deformity, healing fractures, and ulceration. The most common site of involvement in foot is midfoot, but can involve other sites also. ${ }^{14,34}$ Acute stage of CNA can be misdiagnosed as cellulitis, deep vein thrombosis, osteomyelitis, and inflammatory arthropathy. ${ }^{17}$ The other differential diagnosis should be ruled out with proper investigations. Charcot neuroarthropathy with ulcer should be differentiated from osteomyelitis with white blood cell counts and the other investigations, such as magnetic resonance imaging (nonspecific), Indium-111 scintigraphy, and positron emission tomography scan. ${ }^{35,36}$

\section{RADIOGRAPHIC FEATURES OF CNA}

Early-stage radiograph may be normal. The first radiographic features of Charcot foot are diffuse osteopenia, disorganized joints, and soft tissue calcification. Radiograph often shows two patterns: Atrophic pattern where bones are thin with minimal new bone and osteophyte formation. Hypertrophic pattern shows extensive fragmentation, huge haphazard osteophytes, and callus formation with foot taking the form of bag of bone appearance. ${ }^{37}$ Radiological parameters used to assess severity of deformity are talometatarsal angle in lateral and dorsoplantar views, calcaneo - 5th metatarsal angles in lateral view. Comparison of angles pre- and postoperatively helps to know the adequacy of deformity correction. $^{38}$

\section{MANAGEMENT OF MIDFOOT CNA}

The best treatment is early diagnosis and identification of foot at risk, followed by proper immobilization till acute phase settles. Pakarinen et $\mathrm{al}^{39}$ analyzed long-term effects of Charcot foot on patient's lives and found that the need for surgical interventions tends to increase 4 years post diagnosis of Charcots foot and delaying diagnosis by 3 months leads to poor functional outcome. Method of management is largely based on Eichenholtz stages of disease and location of disease radiologically. ${ }^{1}$ Goal of treatment as proposed by Pinzur is to create osseous stable, plantigrade foot, prevention of ulcer and to create foot which can support ambulation with permanent footwear. ${ }^{6,12}$

\section{Nonoperative Treatment}

Armstrong et $\mathrm{al}^{19}$ reported that $75 \%$ of $\mathrm{CNA}$ patients can be treated with nonoperative method and surgery is indicated only in $25 \%$ cases with $2 / 3$ rd requiring exostectomy and $1 / 3$ rd requiring arthrodesis. Nonoperative treatment is 
the mainstay of treatment for acute phase CNA. The aim of nonoperative treatment is to reduce stress on midfoot area, immobilization of joints, and prevention of deformity progression. It consists of immobilization of foot in total contact cast (TCC) and encouraging weightbearing walking to prevent stress fracture, ulceration in contralateral foot ${ }^{40}$ even though reported prevalence of bilateral CNA varies from $9 \%$ to $2 / 3$ rd of cases in some series. ${ }^{41}$ Total contact cast should be changed every 2 weeks to accommodate for the change in volume of foot ${ }^{41}$ and to be continued till quiescent stage, indicated by reduced swelling, temperature, erythema, and radiological evidence of bridging trabeculae. Duration of TCC varies with location of disease, with forefoot CNA having faster healing rates compared to other sites and mean duration of immobilization being 86 days. ${ }^{42}$ Mean duration of immobilization for midfoot Charcot is 4 months (4-6 months) but some may require up to 12 months. ${ }^{43}$ Once the quiescent stage sets, TCC is replaced with removal walking cast and finally, permanent therapeutic footwear applied. ${ }^{44}$ Studies have reported $60 \%$ successful outcome with TCC for midfoot CNA with mean duration of treatment varying 4 to 6 months, with faster healing rates in forefoot followed by ankle $>$ midfoot $>$ hindfoot. $^{42,45,46}$

\section{Drawbacks of Conservative Treatment}

Failure of conservative treatment leads to progressive deformity, recurrent ulceration, osteomyelitis, and amputation. This two-stage approach is associated with increased duration of treatment, high morbidity, cost, and reduced quality of life. ${ }^{13,46}$ Studies have reported recurrent ulceration up to $30 \%$ in patients who are on TCC. ${ }^{47}$ Some studies reported 40 to $50 \%$ of patients who are on TCC may need secondary surgery. Total contact cast in obese patients with insensate foot is difficult as it carries high morbidity and increased risk of ulceration. ${ }^{6,14,46}$

\section{SURGICAL MANAGEMENT OF CNA OF MIDFOOT}

Surgical management guidelines for midfoot CNA are lacking due to insufficient evidence and lack of prospective randomized studies. The surgical procedures done commonly for midfoot CNA are: (1) Arthrodesis, (2) exostectomy, and (3) gastrocnemius or tendoachilles lengthening. Evidence on timing of these surgical interventions and ideal fixation methods is lacking. ${ }^{32}$ In a systemic review by Schneekloth et al, ${ }^{48} 30$ studies consisting of 860 CNA patients who had surgical interventions were analyzed. Surgeries included arthrodesis, exostectomy, debridement of ulcers, drainage of infections, and amputation $(8.9 \%)$. They concluded that timing of surgery and methods of fixation still remain inconclusive.
The basic principles to be followed while performing surgery for CNA are: Surgery should be avoided in acute phase till edema and swelling subside; till then TCC is used; and start of quiescent stage should be confirmed by clinical and radiological evaluation. Arthrodesis should be performed with proper technique using rigid internal fixation, autogenous bone grafting, and operated limb should be immobilized for adequate period allowing limited weightbearing till radiological evidence of healing.

Early vs late surgery: Failure to initiate early treatment carries risk of foot instability, ulceration, and infection. Patients with instability, early Charcot, nonplantigrade foot, impending, or formed ulcer should undergo early surgery as it is found to increase quality of life and reduce cost of treatment. Early surgery also provides longstanding functional outcome without recurrent ulceration or instability and gives walking independence with permanent footwear. ${ }^{13,49}$ Mittlmeier et $\mathrm{al}^{1}$ stated that early surgical intervention helps in timely restoration of plantigrade foot, improves quality of life, and carries complications rates comparable to that after secondary surgery. Eschler et $\mathrm{al}^{50}$ found that even late corrective arthrodesis for patients with nonplantigrade foot provides reasonable reconstruction of foot but carries high chance of reoperations and complications related to soft tissues (76\%) and hardware (43\%).

Preoperative workup should include assessing vascularity of limb by palpation of peripheral pulses, foot swelling should be investigated with Doppler to rule out venous thrombosis, routine weightbearing radiographs, and computed tomography in selected patients with severe deformity is needed for surgical planning.

\section{SURGICAL RECONSTRUCTIVE ARTHRODESIS PROCEDURES (TABLE 3)}

The goal of surgical treatment is not merely salvaging the foot but providing infection-free, ulcer-free, plantigrade osseous stable foot which can accommodate depth inlay therapeutic footwear and provide independent walking. ${ }^{13,46}$ Most of the patients have low physical demand and salvage of foot leads to satisfactory results. ${ }^{51,52}$ Reconstructive procedures of foot are challenging due to poor bone quality, comorbidities, sensory, vascular, and immunity impairment. ${ }^{53}$ But even with advances in fixation devices arthrodesis procedure caries complication rate varying from 10 to $30 \%{ }^{13,14}$ such as implant failure, infection, loss of reduction, hardware failure, nonunion, and wound-healing problems.

\section{INDICATIONS AND CONTRAINDICATIONS}

Indications are: (1) Nonplantigrade foot, (2) impending or established ulceration, (3) severe foot deformity which cannot be accommodated in footwear, (4) early Charcots 
Table 3: Outcomes of case series of midfoot CNA treated with arthrodesis procedures

\begin{tabular}{|c|c|c|c|c|c|c|c|c|}
\hline Study & $\begin{array}{l}\text { No. of } \\
\text { patients }\end{array}$ & $\begin{array}{l}\text { Mean follow-up } \\
\text { (months) }\end{array}$ & $\begin{array}{l}\text { Recurrent } \\
\text { ulceration }\end{array}$ & $\begin{array}{l}\text { Revision } \\
\text { surgery }\end{array}$ & Infection & Nonunion & Amputation & Function AOFAS \\
\hline Mittlmeier et al $(2010)^{1}$ & 22 & 32 & 0 & 4 & 1 & 6 & 0 & $51-84$ \\
\hline Simon et al $(2000)^{54}$ & 14 & 41 & 0 & 0 & 0 & 0 & 0 & Ambulant \\
\hline Myerson et al $(2000)^{81}$ & 30 & 48 & 2 & 1 & 0 & 2 & 0 & Community walker \\
\hline Pinzur and Sostak $(2007)^{13}$ & 51 & 33 & 3 & 8 & - & - & 3 & - \\
\hline Sammarco et al $(2009)^{67}$ & 22 & 52 & 3 & 9 & 1 & 6 & 0 & All ambulant \\
\hline Richter et al $(2015)^{57}$ & 48 & 12 & 6 & 3 & 8 & 1 & 5 & $94 \%$ success \\
\hline Assal and Stern (2009) ${ }^{82}$ & 15 & 42 & 0 & 1 & 1 & 4 & 1 & $14 / 15$ ambulant \\
\hline
\end{tabular}

after acute phase, and (5) CNA with instability. ${ }^{1,2,13,49,54}$ Contraindications ${ }^{55}$ are: (1) High-risk patient for anesthesia due to multiple comorbidities, (2) technically nonreconstructible deformity due to severe bone loss, (3) peripheral vascular disease, (4) high-grade infections and osteomyelitis, and (5) patients who are not willing for extended period of inactivity.

Arthrodesis should be done at both medial and lateral column of foot. ${ }^{56,57}$ Eschler et al $^{56}$ studied patients who had undergone medial column fusion with standalone fusion bolt and it resulted in need for revision surgery in 6 out of 7 cases. The authors concluded the use of medial fusion bolt as a standalone technique carries high-risk of complications and failure of union due to poor stability. So, they recommended the use of additional angular stable plates for medial column and lateral column stabilization for foot at the time of first surgery.

\section{Choice of Implant}

There is no clear evidence regarding ideal implant for internal or external fixation but decision should be based on multiple factors. The commonly used implants are $6.5 \mathrm{~mm}$ long fusion bolts of varying sizes and designs, combination of plate and screws, external fixators, and combination of internal and external skeletal stabilization. Pinzur and Sostak ${ }^{13}$ proposed criteria for implant selection and stated patients with nonplantigrade foot with large bone deformity, longstanding ulcer, infected bone, osteopenia, obesity, or immunocompromised state were found to have more complications and he recommended percutaneous deformity correction and ring external fixators for these patients. Those patients without ulcers, infection, good bone quality, less comorbidities, without obesity carry low-risk of complications and are to be managed with open stabilization and internal fixation. Eschler et $\mathrm{al}^{50}$ found based on above criteria that mean complication in patients with less than two risk factors is 1.3 in comparison to 2.8 in patients with more risk factors.

\section{Midfoot Fusion Bolts}

Charcot neuroarthropathy patients encounter difficulty in limiting weightbearing on operated limb and they are at risk for early implant failure. To overcome this, solid $6.5 \mathrm{~mm}$ intramedullary bolt was designed. These bolts were found to withstand higher load and have reduced risk of implant failure in comparison to plates. ${ }^{1,2}$ Jones $^{58}$ has described midfoot fusion with the use of large intramedullary locking bolts called "beaming." Richter et $\mathrm{al}^{57}$ in their study reported the use of midfoot fusion bolts for realignment and fixation of severe midfoot CNA in 47 cases. He stated midfoot fusion bolts provide stable fixation, high union rates (98\%) with minimal loss of correction. They had complications like woundhealing problems in $21 \%$ cases, recurrent ulceration in $13 \%$, major amputations in $4 \%$, minor amputations in $6 \%$, and $6 \%$ required revision surgery due to loss of correction. They found complications were more when only one fusion bolt is used and when Gastrocnemius was not lengthened. Waldecker ${ }^{59}$ performed midfoot fusion using screws and bone grafting in 12 patients (six with ulcer rest without ulcer) and were followed up till 2.4 years. Ten patients achieved osseous union by mean of 4.3 months, one patient had infection, one had unstable nonunion and recurrence of deformity, and all were ambulant by 7 months. Author concluded that midfoot fusion with open reduction and arthrodesis with screws provides good results. Butt et al ${ }^{60}$ studied $6 \mathrm{~mm}$ Synthes midfoot fusion bolt for medial column fusion in nine cases and found high-rate complications like screw migration, loosening, and finally concluded that $6 \mathrm{~mm}$ Synthes bolt fails to provide adequate stability for midfoot fusion and advised against routine use of it (Figs 1A to G).

\section{Surgical Technique (Figs 2A to J)}

Surgery is performed in supine position under aseptic precautions and tourniquet control. Initially, gastrocnemius or tendoachilles lengthening done in patients found to have equinus contracture with separate incision at musculotendinous junction of gastrocnemius or by percutaneous method for tendoachilles lengthening respectively. Two incisions dorsomedial and dorsolateral are employed for medial and lateral column exposure and fusion. Dorsomedial incision starts from medial malleolus to first metatarsophalangeal joint. Interval 


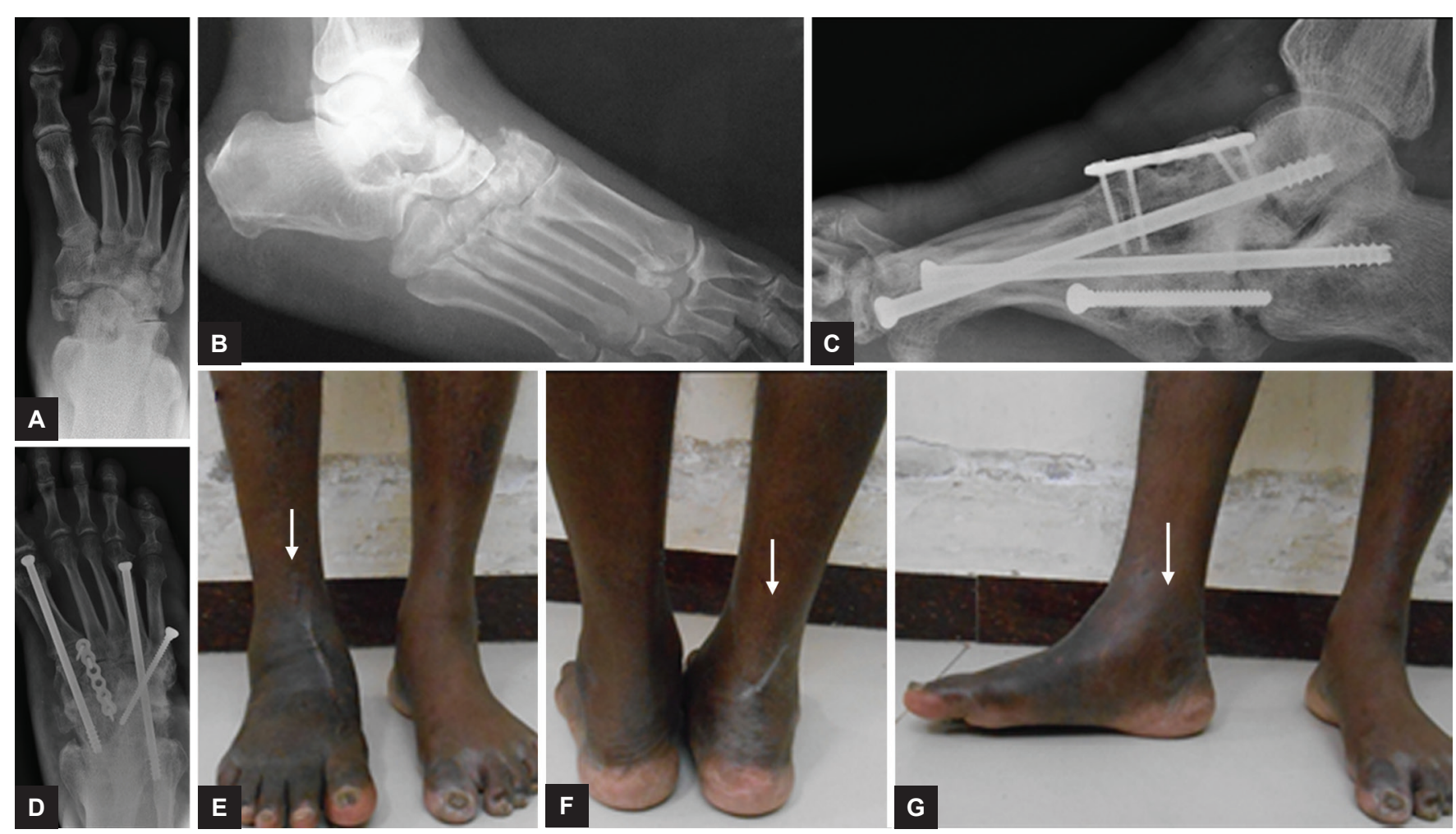

Figs 1A to G: Case example: (A \& B) Plain radiographs showing Eichenholtz grade I charcots arthropathy in 58 years male involving midtarsal joints of right foot with midtarsal collapse; $(C \& D)$ radiographs at 6 months following medial and lateral column fusion with $6.5 \mathrm{~mm}$ AO cannulated screws, additional medial column plate and screws at lateral column showing well consolidated arthrodesis; and $(E$ to $G$ ) clinical picture at 6 months follow-up showing plantigrade right foot with well corrected rocker bottom deformity

developed between tibialis anterior medially and extensor hallucis longus laterally to expose talonavicular joint, naviculocunieform joint, and cunieform-first metatarsal joint. Dorsolateral incision starts in front of lateral malleolus ending at base of 4 th and 5 th metatarsal bone. Here calcaneocuboid, cuboid 4th and 5th metatarsal joints, 2nd to 3rd tarsometatarsal joints were exposed. Synovium, cartilage, sclerotic bone excised to create healthy bleeding surface of bones. Usually, midfoot CNA presents as rocker bottom deformity and forefoot abduction with apex of deformity at plantar and medial aspect respectively. Osteotomizing and excision of more bone at apex of deformity followed by plantar aspect ligament release aids in deformity correction. If there is extensive bone loss after debridement, tricortical iliac crest bone grafts were used to bridge and maintain length of foot. Midfoot collapse and forefoot abduction are corrected by plantarflexion and adduction of metatarsal bones so as to align with corresponding tarsal bones. Final fixation is carried out with intramedullary $6.5 \mathrm{~mm}$ fusion bolts with or without additional low profile plates and screws. Stab incision made at head of 1st metatarsal bone, using curved hemostat metatarsal head reached by bluntly spreading the soft tissues. Holding the foot in alignment, a $2 \mathrm{~mm}$ guide pin is passed in antegrade manner through plantar aspect of head of first metatarsus along first metatarsus, medial cuneiform, Navicula (or strut grafts when used), and talar body under image intensifier control. Through 2nd stab incision, a 2nd guide pin passed through plantar aspect of head of 4 th metatarsus across 4 th metatarsus, cuboid, and calcaneum. The position of guide pin confirmed with anteroposterior, lateral, oblique, and axial images of image intensifier. Reaming done over guide pin using $4.5 \mathrm{~mm}$ cannulated reamer and appropriate size $6.5 \mathrm{~mm}$ AO long, cannulated, short-threaded compression screws are inserted to achieve compression in plantigrade position. Threaded portion of screws should cross talus or calcaneum completely to achieve good compression. If fixation is not stable enough, additional $6.5 \mathrm{~mm} \mathrm{AO}$ screw was passed across 2 nd metatarsus through intermediate cuneiform, navicular, and talus or low-profile plates are used to augment medial column. Rest of gaps were packed with iliac crest bone grafts. Closure done over suction drain, and below the knee Plaster of Paris cast was applied.

\section{Postoperative Protocol}

Postsurgery, antibiotic therapy should be continued for 3 days and nonweightbearing is allowed with foot immobilized in cast for 6 to 8 weeks till swelling reduces, later partial weightbearing with removable cast walker for up to 3 months is advised, followed by full weightbearing with permanent footwear. ${ }^{41}$ 


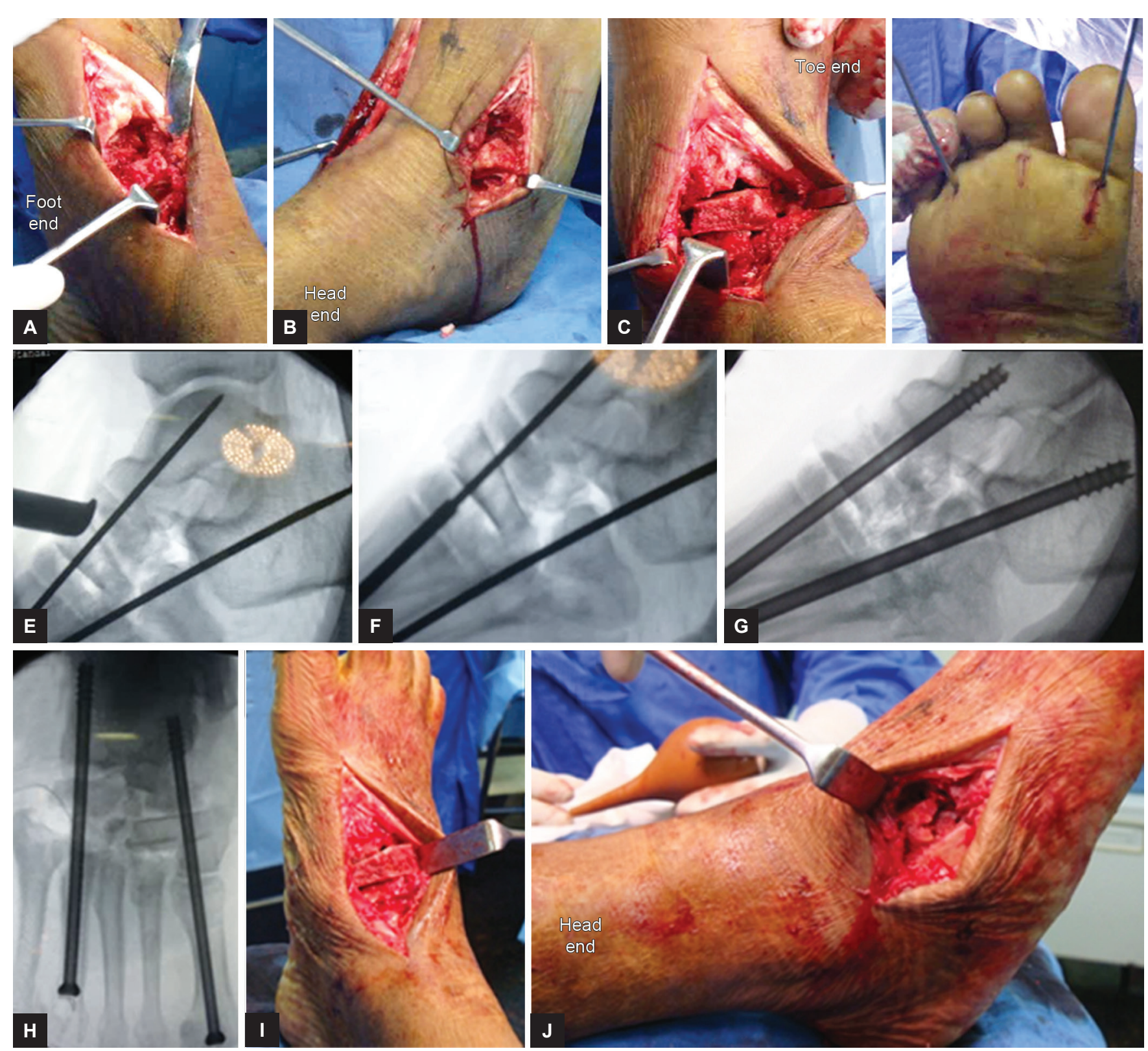

Figs 2A to J: Description of surgical technique: (A) Patient in supine position dorsomedial incison used to expose and debride talonavicular, naviculocunieform, cuneiform first metatarsal joints picture shows post debridement bone gaps; (B) post debridement picture shows dorsolateral incision exposing calcaneocuboid, cuboid 4th and 5th metatarsal joints; (C) bone gap packed with tricortical iliac crest bone graft to maintain length of medial column; (D) guide pin $(2 \mathrm{~mm})$ passed through stab incisions on plantar aspect of $1 \mathrm{st}$ and 4 th metatarsal head along medial (through tricortical graft also) and lateral column of foot; (E) guide pin position confirmed with image intensifier; (F) reaming done with $4.5 \mathrm{~mm}$ cannulated reamer over the guide pin; $(\mathrm{G} \& \mathrm{H})$ AO $6.5 \mathrm{~mm}$ long cannulated short threaded screws inserted along medial and lateral column of foot; and ( $\& \mathrm{~J})$ Intraoperative picture after final screw fixation and bone grafting of the gaps

\section{Arthrodesis with Plates}

Garchar et $\mathrm{al}^{61}$ studied the use of plating in plantar surface of medial column in lisfranc fracture dislocations secondary to CNA in 24 patients. At average follow-up of 38 months union was achieved in 24 of 25 feet and average time to ambulation was 11.68 weeks and the author concluded that the use of plantar plate provides sturdy construct for arthrodesis and ambulation. Nasser et $\mathrm{al}^{62}$ described medial column fusion for various indications with anatomical distal fibular locking plates and stated that technique provides rigid fixation for at risk bone.

\section{Hybrid Fixation}

Sometimes it may be useful to use both internal and external fixation methods to provide stable construct. Smith and Moore ${ }^{63}$ described hybrid fixation consisting of medial column fusion with plate and protection of construct and correction with external ring fixator. Matsumoto and Parekh ${ }^{53}$ described the use of multiaxial correction monolateral external fixation with or without plate for midfoot Charcot arthropathy correction. Out of 11 cases, all cases went onto union without amputation, all were ambulant, and no pin site infections occurred. 
The authors concluded that monolateral external fixator is an easy and acceptable method. Hegewald et $\mathrm{al}^{64}$ reported the use of both external and internal fixation in management of 22 cases of CNA. During mean follow-up 58.6 months foot was salvaged in 20 cases (90.91\%) with satisfactory radiographic alignment and 2 cases underwent amputation (9.09\%). Complications like wound dehiscence $-36.36 \%$, pin tract infection $45.45 \%$, and superficial infection $-40.91 \%$ were reported. The authors concluded that limb salvage rate in CNA is improving due to newer developments in internal and external fixation.

\section{Minimally Invasive Surgical Procedures}

Open major reconstructive surgeries involve excision of bone, deformity correction, and internal fixation which carries risk of delayed wound healing, shortening of foot, incomplete correction of deformity, implant failure, infection, and need for cast or brace for longer periods with complications ranging from 10 to $30 \%{ }^{13,14}$ To minimize these complications, Delhey et al ${ }^{65}$ described closed reposition and circular fixator stabilization treatment for midfoot CNA. Lamm et $\mathrm{al}^{66}$ described deformity correction by distraction using Taylor spatial frame, followed by arthrodesis with minimally invasive internal fixation. Among 11 feet in their study all had satisfactory radiological outcomes; no patient had deep infection, screw failure, recurrent ulceration, and amputation. The most common complication in their series was pin tract infection -11 , pin and ring breakage, and need for readjustment of frame.

\section{Arthrodesis of Midfoot CNA associated with Ulcer or Infection}

Surgical reconstruction in the presence of ulcers is often feared due to risk of infection. Some series recommended postponing of surgery till ulcer heals or advocated external fixators to reduce complications. ${ }^{49,67}$ This complicated scenario demands stepwise approach aiming at eradication of infection, deformity correction, and wound coverage. ${ }^{68}$ Managing ulcers of CNA require multidisciplinary approach; Sinkin et al $^{69}$ managed 314 wounds in 259 diabetic patients with various methods like primary closure (15\%), delayed primary closure (18.01\%), bioengineered tissues (31.6\%), skin grafts (21.2\%), local flaps $(7.8 \%)$, and free flaps $(2.6 \%)$. They found that $65.1 \%$ wound healed in time and $35.6 \%$ required amputations and finally concluded that despite multidisciplinary approach most of patients are at risk of major or partial foot amputations with more proximal wounds are at highest risk. External fixators are indicated when CNA is associated with infection. Capobianco and Zgonis ${ }^{68}$ described local muscle flap of abductor hallucis for wound coverage and use of ring external fixators for stabilization of foot. Pinzur et $\mathrm{al}^{70}$ managed 73 cases of CNA with infection by single-stage radical excision of infected tissue, deformity correction, and maintenance of correction with circular ring external fixators followed by parenteral antibiotics as per the culture sensitivity. Fixators were retained for 8 to 12 weeks, later TCC was applied for 4 to 6 weeks. They reported $95.7 \%$ of limb salvage with ability to ambulate in therapeutic footwears. Farber et $\mathrm{al}^{71}$ managed CNA of midfoot with associated ulcer with debridement, corrective osteotomy, external skeletal stabilization, and culture-specific antibiotics. They reported that all patients were able to wear footwear by 12 to 49 months follow-up. In another study by Pinzur ${ }^{49}$ CNA with infection was managed with tendoachilles lengthening, excision of infected tissue, deformity correction, and stabilization with three-level ring fixator followed by antibiotic therapy. They reported all patients were ulcer-free, infection-free and were ambulant. Dalla Paola et $\mathrm{al}^{72}$ managed 45 cases of CNA with infection by debridement and external skeletal stabilization and the authors reported that 39 cases had no infection and foot salvaged. In one study, it was concluded that the site of disease and grade of osteomyelitis has no bearing on limb salvagibility. ${ }^{73}$

But some studies have reported good outcome with internal fixation in the presence of ulcer. In a series by Mittlmeier et $\mathrm{al}^{1}$, one-third of patients had ulcers preoperatively and all ulcers healed postsurgery using plates or screws without any major complications. Altindas et $\mathrm{al}^{74}$ described two-stage Boyd operation (talectomy and tibiocalcaneal nail fusion) for complicated infected CNA of foot, where 11 patients were managed with this method and all attained ulcer-free ankylosed foot at mean follow-up of $2.1 \pm 0.8$ years.

\section{Tendoachilles or Gastrocnemius Lengthening}

Boffeli and Tabatt ${ }^{75}$ described the use of simple lessinvasive surgical procedures in the form of tendoachilles lengthening, plantar fasciotomy, tendon transfers in earlystage CNA before the development of rigid deformed foot. The principles of these interventions are to eliminate deforming forces acting across the joint. The goal is to provide braceble foot, halting development of deformities, and avoiding possible need for major reconstructive surgeries. Equinus contracture is the most important factor responsible for increased plantar pressures, plantar ulceration, and progression to midfoot collapse. ${ }^{29,30,76}$ Lengthening of gastrocnemius or tendoachilles reduces shearing forces passing through the midfoot, thereby may prevent midfoot collapse. Surgery is based on Silfverskiold test wherein dorsiflexion at ankle joint is 
tested with knee in extension and flexion. Positive test is when dorsiflexion improves with knee flexion, suggesting tightness of gastrocnemius. Here gastrocnemius is transacted transversely at muscle tendon junction using $3 \mathrm{~cm}$ incision over posteromedial aspect of leg. Later, suture was placed at tendon stump to stabilize the tendon in correct length. ${ }^{57}$ In patients with negative Silfverskiold test, tendoachilles was lengthened by percutaneous method. ${ }^{1}$

\section{Exostectomy}

Midfoot collapse in CNA foot leads to rocker bottom deformity, with apex of deformity being plantar ward. This causes skin breakage and ulceration. ${ }^{3}$ Surgeries addressing plantar bone prominence like exostectomy aids in ulcer healing. Laurinaviciene et $\mathrm{al}^{77}$ described exostectomy for chronic midfoot ulcers with Charcot deformities. Pakarinen et $\mathrm{al}^{39}$ found in his study that exostectomy resulted in successful ulcer healing in $62 \%$ of cases.

\section{Predictors of Good Outcome after Surgery}

Use of more than 1 fusion bolts is associated with lower failure rates and minimal loss of correction. ${ }^{56}$ Richter et $\mathrm{al}^{57}$ reported the use of three fusion bolts: One in medial column, one in lateral column, and one for subtalar joint, has least complications. Gastrocnemius or tendoachilles lengthening is associated with lower failure rates as it eliminated deforming force on foot. ${ }^{78}$

\section{Complications of Surgery: Summary in Table 3}

Richter et $\mathrm{al}^{57}$ reported $63.8 \%$ adverse events in patients undergoing surgery for CNA, indicating morbidity associated with the pathology. Hartig et $\mathrm{al}^{79}$ in a systemic review concluded even with strict aseptic precautions and vast experience complications can occur with CNA. The authors concluded early diagnosis of CNA, timely intervention before ulceration, and optimal treatment of comorbidities help to reduce the complications.

The common complications are:

- Wound-healing problems, recurrent ulceration.

- Loss of correction - Can lead to nonunion and reulceration. Literature as reported loss of correction ranging from 16 to $60 \% .{ }^{1,2,67}$ But with the use of intramedullary solid fusion bolts the reported rate of loss of correction is $6 \% .57$

- Hardware failure-Mertinus Richter reported revision surgery due to instability and loss of correction in 6\% of cases.

- Deep infection - reported rate is up to $30 \%$.

- Nonunion - reported rate is up to $30 \%$ and it often coincides with hardware failure.

- Fibrous union - if stable does not require revision.

\section{Amputation}

Amputation is indicated in cases where CNA is complicated with osteomyelitis with threatening sepsis. Dalla Paola et $\mathrm{al}^{73}$ stated in his study that even in CNA with osteomyelitis single- or double-stage arthrodesis, with the use of external fixation provides good outcome and is a reasonable alternative to below knee amputation. Evans et $\mathrm{al}^{80}$ analyzed outcomes in diabetic patients undergoing amputation and found that mortality and morbidity in patients undergoing proximal forefoot and midfoot amputation is less in comparison to below knee amputation. Authors suggested aggressive efforts to salvage the limb with proximal forefoot and midfoot amputation first, before considering high-level limb amputations (below knee amputation).

\section{CONCLUSION}

Charcot neuropathy of midfoot is most debilitating orthopedic condition which warrants early diagnosis, aggressive immobilization, and timely reconstructive procedures to reduce ulceration and to restore stable plantigrade foot for independent ambulation.

\section{REFERENCES}

1. Mittlmeier T, Klaue K, Haar P, Beck M. Should one consider primary surgical reconstruction in charcot arthropathy of the feet? Clin Orthop Relat Res 2010 Apr;468(4):1002-1011.

2. Richter M, Zech S. Four-stage regimen for operative treatment of diabetic foot ulcer with deformity - results of 300 patients. Foot Ankle Surg 2012 Dec;18(4):247-254.

3. Lesko P, Maurer RC. Talonavicular dislocations and midfoot arthropathy in neuropathic diabetic feet. Clin Orthop Relat Res 1989 Mar;240:226-231.

4. Dhawan V, Spratt KF, Pinzur MS, Baumhauer J, Rudicel S, Saltzman CL. Reliability of AOFAS diabetic foot questionnaire in Charcot arthropathy: stability, internal consistency and measurable difference. Foot Ankle Int 2005 Sep;26(9): 717-731.

5. Chammas NK, Hill RL, Foster AV, Edmonds ME. Premature mortality in Charcot patients. Diabet Med 2001;18 (Suppl 2):S78.

6. Pinzur MS. Current concepts review: Charcot arthropathy of the foot and ankle. Foot Ankle Int 2007 Aug;28(8):952-959.

7. Saltzman CL, Hagy ML, Zimmerman B, Estin M, Cooper R. How effective is intensive nonoperative initial treatment of patients with diabetes and Charcot arthropathy of the feet? Clin Orthop Relat Res 2005 Jun;435:185-190.

8. Bevilacqua NJ, Rogers LC, Armstrong DG. Diabetic foot surgery: classifying patients to predict complications. Diabetes Metab Res Rev 2008 May-Jun;24 (Suppl 1):S81-S83.

9. Pinzur MS, Shields N, Trepman E, Dawson P, Evans A. Current practice patterns in the treatment of Charcot foot. Foot Ankle Int 2000 Nov;21(11):916-920.

10. Pinzur MS, Lio T, Posner M. Treatment of Eichenholtz stage I Charcot foot arthropathy with a weightbearing total contact cast. Foot Ankle Int 2006 May;27(5):324-329. 
11. Rammelt S, Zwipp H, Schneiders W. Treatment strategies for Charcot-osteoarthropathy. Osteologie 2014;23:107-116.

12. Wukich DK, Sung W, Wipf SA, Armstrong DG. The consequences of complacency: managing the effects of unrecognized Charcot feet. Diabet Med 2011 Feb;28(2):195-198.

13. Pinzur MS, Sostak J. Surgical stabilization of nonplantigrade Charcot arthropathy of the midfoot. Am J Orthop 2007 Jul;36(7):361-365.

14. Pakarinen TK, Laine HJ, Honkonen SE, Peltonen J, Oksala H, Lahtela J. Charcot arthropathy of the diabetic foot. Current concepts and review of 36 cases. Scand J Surg 2002;91(2): 195-201.

15. Jordan WR. Neuritic manifestations in diabetes mellitus. Arch Intern Med 1936;57(2):307-312.

16. Sanders LJ, Frykberg RG. Diabetic neuropathic osteoarthropathy: the Charcot foot. In: Fryberg RG, editor. The high risk foot in diabetes mellitus. New York (NY): Churchill Livingstone; 1991. p. 297-338.

17. Sinha S, Munichoodappa C, Kozak GP. Neuroarthropathy (Charcot's joints) in diabetes mellitus: a clinical study of 101 cases. Medicine (Baltimore) 1972 May;51(3):191-210.

18. Lavery LA, Wunderlich RP, Tredwell J, Boulton AJ. Diabetic foot syndrome: evaluating the prevalence and incidence of foot pathology in Mexican Americans and non-Hispanic whites from a diabetes disease management cohort. Diabetes Care 2003 May;26(5):1435-1438.

19. ArmstrongDG, ToddWF, Lavery LA,Harkless LB, BushmanTR. The natural history of acute Charcot's arthropathy in a diabetic foot specialty clinic. J Am Podiatr Med Assoc 1997 Jun;87(6):272-278.

20. Cavangh PR, Young MJ, Adams JE, Vickers KL, Boulton AJ. Radiographic abnormalities in the feet of patients with diabetic neuropathy. Diabetes Care 1994 Mar;17(3):201-209.

21. Shaw JE, Boulton AJM. The Charcot foot. Foot 1995;5:65-70.

22. Charcot JM. Sur quelaques arthropathies qui paraissent depender d'une lesion du cerveau ou de la moele epiniere. Arch Des Physiol Norm Path 1868;1:161-171.

23. Eloeser L. On the nature of neuropathic affections of the joint. Ann Surg 1917 Aug;66(2):201-206.

24. Brower AC, Allman RM. Pathogenesis of the neuropathic joint: neurotraumatic vs neurovascular. Radiology 1981 May;139(2):349-354.

25. Finsterbush A, Friedman B. The effect of sensory denervation on rabbits' knee joints. J Bone Joint Surg Am 1975 Oct;57(7):949-957.

26. Archer AG, Roberts VC, Watkins PJ. Blood flow patterns in painful diabetic neuropathy. Diabetologia 1984 Dec;27(6): 563-567.

27. Eichenholtz SN. Charcot joints. Springfield (IL): Charles C Thomas; 1966.

28. Brower AC, Allman RM. The neuropathic joint: a neurovascular bone disorder. Radiol Clin North Am 1981 Dec;19(4): 571-579.

29. Stone NC, Daniels TR. Midfoot and hindfoot arthrodesis in diabetic Charcot arthropathy. Can J Surg 2000 Dec;43(6): 449-455.

30. Fujita T, Shiba H, Van Dyke TE, Krihara H. Differential effects of growth factors and cytokines on the synthesis of SPARC, DNA, fibronectin and alkaline phosphatase activity in human periodontal cells. Cell Biol Int 2004;28(4):281-286.

31. Petrova NL, Foster AV, Edmonds ME. Calcaneal bone mineral density in patients with Charcot neuropathic osteoarthropa- thy: differences between Type 1 and Type 2 diabetes. Diabet Med 2005 Jun;22(2):756-761.

32. Lowery NJ, Woods JB, Armstrong DG, Wukich DK. Surgical management of Charcot neuroarthropathy of the foot and ankle: a systematic review. Foot Ankle Int 2012 Feb;33(2): 113-121.

33. Wukich DK, Sung W. Charcot arthropathy of the foot and ankle: modern concepts and management review. J Diabetes Complications 2009 Nov-Dec;23(6):409-426.

34. Pinzur MS, Sammarco VJ, Wukich DK. Charcot foot: a surgical algorithm. Instr Course Lect 2012;61:423-438.

35. Marcus CD, Ladam-Marcus VJ, Leone J, Malgrange D, BonnetGausserand FM, Menanteau BP. MR imaging of osteomyelitis and neuropathic osteoarthropathy in the feet of diabetics. Radiographics 1996 Nov;16(6):1337-1348.

36. Hopfner S, Krolak C, Kessler S, Tiling R. Preoperative imaging of Charcot neuroarthropathy: does the additional application of (18)F-FDG-PET make sense? Nukleamedizin 2006;45(1): $15-20$.

37. Jude EB, Boulton AJM. End stage complications of diabetic neuropathy. Diabetes Rev 1999;7:395-410.

38. Richter M, Zech S. Lengthening osteotomy of the calcaneus and flexor digitorum longus tendon transfer in flexible flatfoot deformity improves talo-1st metatarsal-index, clinical outcome and pedographic parameter. Foot Ankle Surg 2013 Mar;19(1):56-61.

39. Pakarinen TK, Laine HJ, Mäenpää $H$, Mattila $P$, Lahtela J. Long-term outcome and quality of life in patients with Charcot foot. Foot Ankle Surg 2009;15(4):187-191.

40. Armstrong DG, Liswood PL, Todd WF. The contralateral limb during total contact casting: a dynamic pressure and thermometric analysis. J Am Podiatr Med Assoc 1995 Dec;85(12):733-737.

41. Armstrong DG, Lavery LA. Acute Charcot's arthropathy of the foot and ankle. Phys Ther 1998 Jan;78(1):74-80.

42. Sinacore DR. Acute Charcot arthropathy in patients with diabetes mellitus: healing times by foot location. J Diabetes Complications 1998 Sep-Oct;12(5):287-293.

43. Vella S, Cachia MJ. Charcot neuroarthropathy: pathogenesis, diagnosis and medical management. Malta Med J 2008 Sep;20(3):13-19.

44. Lavery LA, Vela SA, Lavery DC, Quebedaux TL. Reducing dynamic foot pressures in high-risk diabetics with foot ulcerations: a comparison of treatments. Diabetes Care 1996 Aug;19(8):818-821.

45. Frykberg RG, Zgonis T, Armstrong DG, Driver VR, Giurini JM, KravitzSR, Landsman AS, Lavery LA, Moore JC, Schuberth JM, et al. Diabetic foot disorders: a clinical practice guideline (2006 revision). J Foot Ankle Surg 2006 Sep-Oct;45 (Suppl 5):S1-S66.

46. Pinzur M. Surgical versus accommodative treatment for Charcot arthropathy of the midfoot. Foot Ankle Int 2004 Aug;25(8):545-549.

47. Guyton GP. An analysis of iatrogenic complications from the total contact cast. Foot Ankle Int 2005 Nov;26(11):903-907.

48. Schneekloth BJ, Lowery NJ, Wukich DK. Charcot neuroarthropathy in patients with diabetes: an updated systematic review of surgical management. J Foot Ankle Surg 2016 May-Jun;55(3):586-590.

49. Pinzur MS. Neutral ring fixation for high-risk nonplantigrade Charcot midfoot deformity. Foot Ankle Int 2007 Sep;28(9): 961-966. 
50. Eschler A, Gradl G, Wussow A, Mittlmeier T. Late corrective arthrodesis in nonplantigrade diabetic Charcot midfoot disease is associated with high complication and reoperation rates. J Diabetes Res 2015;2015:246-792.

51. Papa J, Myerson M, Girard P. Salvage with arthrodesis, in intractable diabetic neuropathic arthropathy of the foot and ankle. J Bone Joint Surg Am 1993 Jul;75(7):1056-1066.

52. Stuart MJ, Morrey BF. Arthrodesis of the diabetic neuropathic ankle joint. Clin Orthop 1990 Apr;253:209-211.

53. Matsumoto T, Parekh SG. Midtarsal reconstructive arthrodesis using a multi-axial correction fixator in Charcot midfoot arthropathy. Foot Ankle Spec 2015 Dec;8(6):472-478.

54. Simon SR, Tejwani SG, Wilson DL, Santner TJ, Denniston NL. Arthrodesis as an early alternative to nonoperative management of Charcot arthropathy of the diabetic foot. J Bone Joint Surg Am 2000 Jul;82-A(7):939-950.

55. Mittlmeier T, Eschler A. Corrective arthrodesis of midfoot Charcot neuroosteoarthropathy with internal fixation. Oper Orthop Traumatol 2015 Apr;27(2):139-153.

56. Eschler A, Wussow A, Ulmar B, Mittlmeier T, Gradl G. Intramedullary medial column support with the Midfoot Fusion Bolt (MFB) is not sufficient for osseous healing of arthrodesis in neuroosteoarthropathic feet. Injury 2014 Jan;45 (Suppl 1):S38-S43.

57. Richter M, Mittlmeier T, Rammelt S, Agren PH, Hahn S, Eschler A. Intramedullary fixation in severe Charcot osteoneuroarthropathy with foot deformity results in adequate correction without loss of correction - results from a multicentre study. Foot Ankle Surg 2015 Dec;21(4):269-276.

58. Jones CP. Beaming for Charcot foot reconstruction. Foot Ankle Int $2015 \mathrm{Jul} ; 36(7): 853-859$.

59. Waldecker U. Arthrodesis with subsequent screw fixation in the treatment of diabetic Charcot hind- and midfoot arthropathy. Z Orthop Unfall 2011 Aug;149(4):402-406.

60. Butt DA, Hester T, Bilal A, Edmonds M, Kavarthapu V. The medial column Synthes Midfoot Fusion Bolt is associated with unacceptable rates of failure in corrective fusion for Charcot deformity: results from a consecutive case series. Bone Joint J 2015 Jun;97-B(6):809-813.

61. Garchar D, DiDomenico LA, Klaue K. Reconstruction of Lisfranc joint dislocations secondary to Charcot neuroarthropathy using a plantar plate. J Foot Ankle Surg 2013 May-Jun;52(3):295-297.

62. Nasser EM, LaPorta GA, Trott K. Medial column arthrodesis using an anatomic distal fibular locking plate. J Foot Ankle Surg 2015 Jul-Aug;54(4):671-676.

63. Smith WB, Moore CA. A proposed treatment algorithm for midfoot Charcot arthropathy. Foot Ankle Spec 2012 Feb;5(1):60-64

64. Hegewald KW, Wilder ML, Chappell TM, Hutchinson BL. Combined internal and external fixation for diabetic Charcot reconstruction: a retrospective case series. J Foot Ankle Surg 2016 May-Jun;55(3):619-627.

65. Delhey P, Bürklein D, Kessler S, Volkering C. Closed reposition of an acute midfoot luxation fracture in Charcot arthropathy with the ring fixator. Unfallchirurg 2010 Jul;113(7): 594-597.

66. Lamm BM, Gottlieb HD, Paley D. A two-stage percutaneous approach to Charcot diabetic foot reconstruction. J Foot Ankle Surg 2010 Nov-Dec;49(6):517-522.
67. Sammarco VJ, Sammarco GJ, Walker EW Jr, Guiao RP. Midtarsal arthrodesis in the treatment of Charcot arthropathy. J Bone Joint Surg Am 2009 Jan;91(1):80-91.

68. Capobianco CM, Zgonis T. Abductor hallucis muscle flap and staged medial column arthrodesis for the chronic ulcerated Charcot foot with concomitant osteomyelitis. Foot Ankle Spec 2010 Oct;3(5):269-273.

69. Sinkin JC, Reilly M, Cralley A, Kim PJ, Steinberg JS, Cooper P, Evans KK, Attinger CE. Multidisciplinary approach to soft-tissue reconstruction of the diabetic Charcot foot. Plast Reconstr Surg 2015 Feb;135(2):611-616.

70. Pinzur MS, Gil J, Belmares J. Deformity and maintenance with ring fixation treatment of osteomyelitis in Charcot foot with single-stage resection of infection, correction of deformity, and maintenance with ring fixation. Foot Ankle Int 2012 Dec;33(12):1069-1074.

71. Farber DC, Juliano PJ, Cavanagh PR, Ulbrecht J, Caputo G. Single stage correction with external fixation of the ulcerated foot in individuals with Charcot neuroarthropathy. Foot Ankle Int 2002 Feb;23(2):130-134.

72. Dalla Paola L, Brocco E, Ceccacci T, Ninkovic S, Sorgentone S, Marinescu M, Volpe A. Limb salvage in Charcot foot and ankle osteomyelitis: combined use single stage/double stage of arthrodesis and external fixation. Foot Ankle Int 2009 Nov;30(11):1065-1070.

73. Dalla Paola L, Carone A, Baglioni M, Boscarino G, Vasilache LJ. Extension and grading of osteomyelitis are not related to limb salvage in Charcot neuropathic osteoarthropathy: a cohort prospective study. Diabetes Complications 2016 MayJun;30(4):608-612.

74. Altindas M, Kilic A, Ceber M. A new limb-salvaging technique for the treatment of late stage complicated Charcot foot deformity: two-staged Boyd's operation. Foot Ankle Surg 2012 Sep;18(3):190-194.

75. Boffeli TJ, Tabatt JA. Minimally invasive early operative treatment of progressive foot and ankle deformity associated with Charcot-Marie-Tooth disease. J Foot Ankle Surg 2015 Jul-Aug;54(4):701-708.

76. Greenhagen RM, Johnson AR, Bevilacqua NJ. Gastrocnemius recession or tendoachilles lengthening for equinus deformity in the diabetic foot? Clin Podiatr Med Surg 2012 Jul;29(3): 413-424.

77. Laurinaviciene R, Kirketerp-Moeller K, Holstein PE. Exostectomy for chronic midfoot plantar ulcer in Charcot deformity. J Wound Care 2008 Feb;17(2):53-55, 57, 58.

78. Anderson JG, Bohay DR, Eller EB, Witt BL. Gastrocnemius recession. Foot Ankle Clin 2014 Dec;19(4):767-786.

79. Hartig N, Krenn S, Trnka HJ. Surgical treatment of the Charcot foot: long-term results and systematic review. Orthopade 2015 Jan;44(1):14-24.

80. Evans KK, Attinger CE, Al-Attar A, Salgado C, Chu CK, Mardini S, Neville R. The importance of limb preservation in the diabetic population. J Diabetes Complications 2011 Jul-Aug;25(4):227-231.

81. Myerson MS, Alvarez RG, Lam PW. Tibiocalcaneal arthrodesis for the management of severe ankle and hindfoot deformities. Foot Ankle Int 2000 Aug;21:643-650.

82. Assal M, Stern R. Realignment and extended fusion with use of a medial column screw for midfoot deformities secondary to diabetic neuropathy. J Bone Joint Surg Am 2009 Apr;91(4):812-820. 